\title{
Herpetic eye attacks: variability of circannual rhythms
}

\author{
D Gamus, A Romano, E Sucher, I E Ashkenazi
}

\begin{abstract}
Background-The issue of seasonal variation of herpetic ocular infections is still controversial. This study was designed to examine whether this variation exists and can be defined as a significant circannual rhythm.

Methods-The patterns of recurrent attacks were monitored in 541 patients over a period of 15 years. Rhythm parameters were analysed according to age, sex, and clinical signs.

Results-The majority of herpetic eye attacks exhibited the highest peak in January $(p<0.04)$, except in the group of atopic children where the incidence of the disease peaked in September $(p<0 \cdot 05)$. Among the various clinical forms, significant circannual periodicities were found only in the occurrence of epithelial herpetic keratitis $(p<0 \cdot 03)$. The rhythms were detected among males $(\mathbf{p}<0.03)$ but not among females. No direct correlation was demonstrated between the presence of the rhythms and the triggering effect of upper respiratory tract infections.

Conclusions-Chronoepidemiological evaluation of individual reactivation patterns may be beneficial to certain patients and contribute to the optimisation of the treatment when prophylaxis is considered.
\end{abstract}

(Br f Ophthalmol 1995; 79: 50-53)

Herpes simplex virus (HSV) eye infections are among the main causes of ocular morbidity and of unilateral corneal blindness. ${ }^{1-5}$

One of the major clinical problems of ocular herpetic diseases resides in the recurrences of the infection. This phenomenon can lead to a serious visual impairment due to corneal structural alteration in adults, and to a secondary amblyopia in children. ${ }^{6}$ There is still no available treatment that eradicates herpetic infection and major efforts are concentrated now on moderating and preventing viral reactivations. The forecasting of the impending recurrence, therefore, may be of great value in the introduction of preventive antiviral therapy.

It is well acknowledged and extensively reviewed that various factors precipitate reactivation of the disease, ${ }^{4} 8$ yet clinical observations show that the majority of recurrences are not preceded by one of the known triggers. ${ }^{9} 10$ Seasonal variations in the occurrence of herpetic keratitis was reported to be the highest in the late autumn and winter months, 91112 presumably because of a higher incidence of upper respiratory tract infections (URTI) during this period. ${ }^{12}$ However, the only study that could demonstrate statistically significant results to support this assumption was based on the evaluation of 27 patients. ${ }^{12}$ Furthermore, these findings were not validated by other studies. ${ }^{1} 1013$ As the recurrences among some of our patients seemed to follow an oscillatory pattern, we have analysed these patterns to examine if they exhibit definable periodicities (rhythms). The object of our study was to investigate the existence of seasonal patterns of HSV ocular attacks in our population and to analyse whether these patterns exhibit significant rhythms unrelated to the triggering effect of URTI. The results were processed to define population groups who would benefit from prophylactic antiviral treatment based on chronoepidemiological evaluation.

\section{Patients and methods}

The study included medical records of 541 patients with 1140 primary and/or recurrent corneal and periocular herpetic attacks, who were referred to the Goldschleger Eye Institute, Sheba Medical Center, Israel, between the years 1971-85. Some patients were referred to our clinic upon the primary attack, while others have joined the follow up after one or more recurrences.

For each patient a fully detailed follow up of herpetic eye attacks was documented including the following variables: sex and age of the patient; date of attack onset; clinical form of the disease; background diseases (with special emphasis on atopic and allergic conditions); and factors related to recurrence.

Clinical diagnosis of herpetic ocular disease was verified by: (a) serial slit-lamp examinations, (b) laboratory studies which included virus isolation in tissue cultures and titre of specific antibodies in blood and tears.

\section{Data analysis}

As the follow up was conducted over a period of 15 years the analysis of seasonal variations and periodicities pertains to the age at which a specific herpetic attack took place. Five age groups were analysed: $0-5$ years (early childhood); 6-10 years; $11-14$ years (adolescence); 15-44 years (young adults); and 45 years and above.

Statistical evaluation of the sex differences and seasonal variation of the disease was carried out by ANOVA and $t$ test (significance 


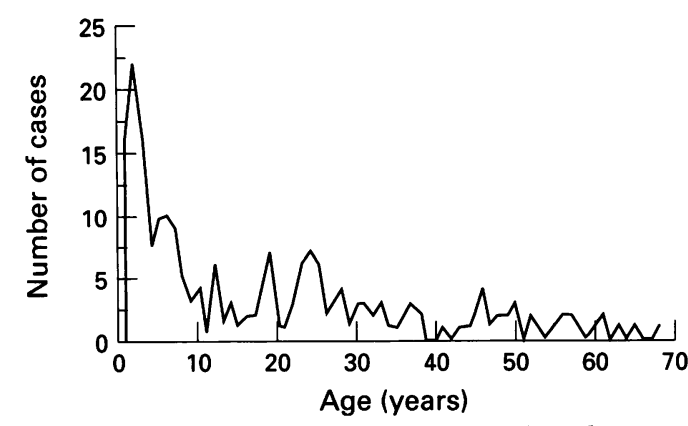

Figure 1 Age distribution of primary herpetic ocular disease.

was determined as $\mathrm{p}<0.05)$. Rhythm parameters and significance were assessed by the best fit cosinor. ${ }^{14} 15$

\section{Results}

Among 541 patients whose records were analysed there were 325 males $(60 \cdot 1 \%)$ and 216 females $(39.9 \%)$ - male to female ratio $1 \cdot 5: 1$. The age of the patients ranged from 4 months to 93 years.

A total of 1140 attacks were recorded: 214 primary and 926 recurrent: 325 males suffered from 679 attacks $(59.6 \%)$ and 216 females from 461 attacks $(40.4 \%)$. The primary (initial) ocular disease occurred primarily $(52 \%)$ in the age group $0-14$ years (Fig 1 ).

Palpebral infections comprised $16.8 \%$ of all herpetic ocular attacks; $63.3 \%$ of the attacks were presented as superficial epithelial (dendritic) keratitis; $16.9 \%$ as stromal keratitis; and in $3 \%$ geographic ulcers were recorded.

The average frequency of herpetic attacks was 1.08 per year (the range varied between four attacks per year to one attack in 10 years), while in $50 \%$ of the patients 0.9 attacks per year were observed.

When the sex dependent occurrence was analysed according to age groups, we found that in children (aged 0-14 years) the male to female ratio was $1: 1.4$ (female preponderance), but in the age group of 15 years and older a highly significant $(\mathrm{p}<0.0005)$ reciprocal ratio of $1 \cdot 8: 1$ was seen.

Among the 106 children, $0-14$ years of age, $49(46 \cdot 2 \%)$ suffered from one of the major allergic disorders: $70 \%$ had allergic asthma, $22 \%$ allergic rhinnitis, and $8 \%$ atopic dermatitis. URTI preceded 134 herpetic eye attacks $(11 \cdot 8 \%)$. The distribution of attacks triggered by URTI during the winter months (November-March) was similar among the

Table 1 Variables of circannual rhythms of herpetic ocular infections

\begin{tabular}{|c|c|c|c|c|}
\hline Group definition & Mean & Amplitude & Acrophase & $p$ Value \\
\hline $\begin{array}{l}\text { Whole } \\
\text { population (1140 attacks) } \\
\text { Children }\end{array}$ & $6 \cdot 32(0.56)$ & $1.89(0.60)$ & 9 January & $<0.04$ \\
\hline $\begin{array}{l}\text { 6-10 years (76 attacks) } \\
\text { Adults }\end{array}$ & $8.50(0.74)$ & $4.53(1.05)$ & 4 December & $<0.008$ \\
\hline $\begin{array}{l}\text { Above } 45 \text { years ( } 323 \text { attacks) } \\
\text { Males ( } 679 \text { attacks) } \\
\text { Primary and recurrent epithelial }\end{array}$ & $\begin{array}{l}2 \cdot 05(0 \cdot 19) \\
3 \cdot 85(0 \cdot 26)\end{array}$ & $\begin{array}{l}0.79(0 \cdot 28) \\
1 \cdot 14(0 \cdot 37)\end{array}$ & $\begin{array}{l}27 \text { December } \\
15 \text { January }\end{array}$ & $\begin{array}{l}<0.05 \\
<0.03\end{array}$ \\
\hline keratitis (721 attacks) & $4 \cdot 76(0.36)$ & $1.63(0.50)$ & 8 January & $<0.03$ \\
\hline
\end{tabular}

Variables (SD) computed by best fit cosinor analysis. Acrophase =computed peak. Amplitude $=$ half the value between peak and trough.

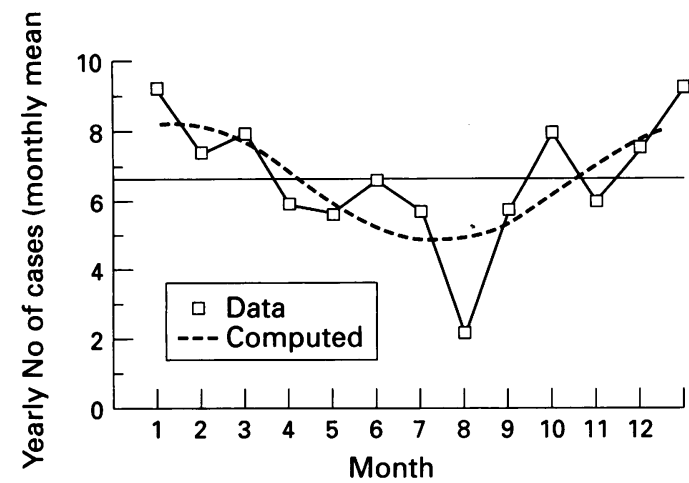

Figure 2 Circannual rhythm of 1140 ocular herpetic attacks (primary and recurrent) within the study group. Data and best fit sine curve. Rhythm significance $p<0.04$. Computed peak 9 fanuary.

both sexes $(5 \cdot 8 \%$ of all documented attacks in males and $6.2 \%$ of females) and among the various clinical forms of ocular herpetic infections.

The mean monthly frequency of ocular herpetic attacks as recorded in the whole patient population, is shown in Figure 2. There was a high incidence of occurrence between October and March with a peak in January $(\mathrm{p}<0.05)$.

ANOVA and $t$ test analyses showed that seasonal time dependency was exhibited by each form of the disease under study: palpebral infections, epithelial keratitis, and stromal keratitis. In atopic children, however, the peak incidence of herpetic infections was documented in September, significantly higher $(p<0.05)$ than in non-atopic children.

To elucidate whether the time dependent occurrence of the attacks follows a significant circannual rhythm, the monthly frequency of the whole study population was analysed by the best fit cosinor method. The results obtained demonstrated an existence of a significant $(\mathrm{p}<0.04)$ circannual rhythm (Fig 2).

Significant circannual rhythms that were detected among the following groups: superficial epithelial (dendritic and punctate) ketatitis, the whole male population, children 6-10 years of age, and adults above 45 years, and are summarised in Table 1. Circannual rhythmic occurrence of the disease was not demonstrated among other clinical forms of herpetic ocular infections, women or other age groups, as categorised in Methods section.

\section{Discussion}

The results of our study which contained 15 years follow up of 541 patients, and which were analysed according to various clinical forms of the disease, sex, and age, confirm for the first time an existence of significant circannual patterns in the occurrence of ocular herpetic infections.

Significant circannual rhythms were found within the whole study group of 1140 ocular herpetic attacks: primary and recurrent (Fig 2), mainly superimposed by the circannual rhythm of superficial epithelial attacks (Table 1). Age and sex dependent analysis exhibited circannual rhythms of herpetic 
ocular attacks among children 6-10 years of age, 45 years and older adults, and males in all age groups (Table 1).

A higher incidence of herpetic eye attacks in our study was documented during the winter months. Bell et al ${ }^{12}$ suggested that respiratory tract infections, which are more common during the cold months, are responsible for the seasonal distribution of recurrences. However, similar seasonal variation was noticed (but not verified statistically) in a study where only 3\% of recurrences related to common cold. ${ }^{9}$ Another study, where $12 \%$ of recurrences were preceded by similar illnesses, ${ }^{10}$ failed to detect any seasonal variation of the disease. In our study, though the distribution of URTI was similar in both sexes we did not detect any significant circannual rhythms among women.

The absence of a definite rhythm in women could be attributed to hormonal changes which occur during the reproductive period and influence the natural course of the herpetic disease. This hypothesis is further supported by the fact that significant circannual patterns were demonstrated by us in the age groups of 6-10 years and of 45 years and above (both sexes). Sex and age (male and child bearing age females) related differences in the expression of seasonal changes were also reported for lymphocyte mitogenic activity, ${ }^{16}$ suggesting that the relation between the neuroendocrine and immune systems affect seasonal rhythms.

It should be emphasised that our group of patients differed from those studied in other reports. ${ }^{10} \quad 1213 \quad 17$ We detected a higher recurrence rate of 1.08 per year compared with $0.66-0.83$ per year, documented in the other studies. ${ }^{12}{ }^{13}$ The latter report ${ }^{13}$ mentions that in patients with more than four attacks the intervals between recurrences were generally shorter $(2 \cdot 2-12$ per year). The age distribution of primary ocular herpetic infection surveyed in London ${ }^{17}$ and in Rochester, Minnesota, ${ }^{2}$ exhibited higher incidence in young adults (15-20 years), while the majority of primary ocular disease in our population was documented during childhood: $33 \%$ of the patients experienced initial ocular infection before the age of 5 years, and $52 \%$ before the age of 14 . The disparity between the various studies could be attributed either to differences in structure of the studied population (number of examined individuals, period of follow up, male to female ratio, age distribution, variability in clinical forms of the disease), or reflect variations in the environmental factors, triggers of reactivation, different strains of the pathogen, as well as different genetic background of the host.

The high percentage of atopic patients observed by us in the population suffering from herpetic diseases is in agreement with another report. ${ }^{18}$ The peak incidence of herpetic ocular infection that was demonstrated in September for this group could be attributed to higher presence of allergens during this season, and thus reflect a masking effect and not the presence of an endogenous process.

It is of interest that of all clinical forms of the disease, only superficial epithelial keratitis exhibited significant circannual periodicity. This could be attributed either to differences in the immunopathogenesis between epithelial keratitis and other clinical manifestations of herpetic ocular infections, ${ }^{4}$ or to a considerably lower occurrence of those diseases in our study.

Circannual and seasonal rhythms of cellular and humoral components of the immune system were detected in experimental models ${ }^{19}$ and in humans. ${ }^{16} 2021$ The studies in humans demonstrated a significant negative correlation between lymphocyte blastogenic responses, ${ }^{16}$ number of circulating natural killer cells, ${ }^{21}$ and the winter months. The levels of other components of the cellular immune system demonstrated significant increases during the spring and autumn season. ${ }^{20}$

We suggest that circannual patterns in the occurrence of epithelial keratitis may stem from seasonal fluctuations in the levels of systemic or local ocular immune mechanisms which may alter the control of latent HSV infection with resultant viral replication in corneal epithelium.

In conclusion, our findings validate the presence of a defined rhythm in the occurrence of herpetic ocular disease. Regardless of whether the rhythm stems from the presence of endogenous components or is affected by exogenous factors, the elucidation of rhythmic pattern in herpetic corneal infections for various populations could be highly beneficial, and may serve as an additional tool to forecast impending reactivations. This knowledge may direct the administration of preventive treatment to certain patients (such as males with recurrent epithelial keratitis) and improve the prognosis of the outcome from recurrent ocular herpetic attacks, by preserving visual acuity. We already started to introduce preventive antiviral therapy in our patients before the anticipated recurrence, according to the individuals' rhythmic patterns. Although it is too early to draw conclusions, the results obtained are encouraging.

This work formed a part of the PhD thesis of D Gamus.

1 Norn MS. Dendritic (herpetic) keratitis. Incidence seasonal variations - recurrence rate - visual impairment - therapy. Acta Ophthalmol 1970; 48: 214-26.

2 Liesegang TJ. A community study of ocular herpes simplex. Cur Eye Res 1991; 10 (suppl): 111-5.

3 Feng CM. The causes of blindness by corneal diseases in 3499 cases. Chung Hua Yen Ko Tsa Chin 1990; 26: 151-3.

4 Easty DL. Viruses of the eye. London: Lloyd-Luke, 1985: chapter 7, 135 .

5 Claoue CMP, Menage MJ, Easty DL. Severe herpetic keratitis. I: Prevalence of visual impairment in a clinic population. Br $\mathcal{F}$ Ophthalmol 1988; 72: 530-3.

6 Poirier RH. Herpetic ocular infections of childhood. Arch Ophthalmol 1980; 98: 704-6.

7 Gamus D, Romano A. Herpetic imprint on privileged areas of its target organs: local latency and reactivation in herpetic keratitis. Metab Ped Syst Ophthalmol 1988; 11: $37-40$.

8 Thygeson P. Historical observations on herpetic keratitis. Surv Ophthalmol 1976; 21: 82-90.

9 Uchio E, Hatano H, Ohno S. Altering clinical features of recurrent herpes simplex virus-induced keratitis. Ann Ophthalmol 1993; 25: 271-6.

10 Jonkers GH. Statistical investigation on the occurrence of herpes simplex corneae. Ophthalmologica 1962; 144: 405-8.

11 Laibson P. Leopold I. An evaluation of double-blind IDU therapy in 100 cases of herpetic keratitis. Trans Am Acad Ophthalmol Otolaryng 1964; 68: 22-34. 
12 Bell DM, Holman RC, Pavan-Langston D. Herpes simplex keratitis: epidemiologic aspects. Ann Ophthalmol 1981; 14: 421-4.

13 Wishart MS, Darougar S, Viswalingam ND. Recurrent herpes simplex virus ocular infection: epidemiological and clinical features. Br 7 Ophthalmol 1987; 71: 669-72.

14 Minors DS, Waterhouse JM. Analysis of biological time series. In: Arendt J, Minors DS, Waterhouse JM, eds. Biological rhythms in clinical practice. London: Wright, 1989: 272.

15 De Prins J, Cornelissen G, Malbecq W. Statistical procedures in chronobiology and chronopharmacology. Ann Rev Chronopharmacol 1986; 2: 27-142.

16 Bochtor FN, Charmy RA, Cooper EL. Seasonal differences in the rhythmicity of human male and female lymphocyte blastogenic response. Immunol Invest 1989; 18: 775-84.

17 Darougar S, Wischart MS, Viswalingam ND. Epidemiological and clinical features of primary herpes simplex ocular infection. $\mathrm{Br} \mathcal{f}$ Ophthalmol 1985; 69: 2-6.

18 Bloch-Michel E, Vamvoukas D, Campinchi R, Nissen F Atopy and herpetic keratitis. In: Sundmacher R, ed. Herpetic eye diseases. Munich: Bergmann Verlag, 1984: 101.

19 Ratajczack HV, Thomas PT, Sothern RB, Vollmuth T, Heck JD. Reproducibility of seasonal effects in antibody formation and host resistance in the outbred mouse. Chronobiol Int 1991; 8: 44-55.

20 Afoke AO, Eeg-Olofsson O, Hed J, Kjellman NI, Lindblom B, Ludvigson J. Seasonal variation and sex differences of circulating macrophages, immunoglobulin and lymphocytes in healthy school children. Scand $\mathcal{f}$ Immunol 1993; 37: 209-15.

21 Kasper S, Rosenthal NE, Barberi S, Williams A, Tamarkin L, Rogers SL, et al. Immunological correlates of seasonal fluctuations in mood and behaviour and their relationship to phototherapy. Psychiatry Res 1991; 36: 253-64. 